\title{
Optimal Timing of Investments to Control Honey Mesquite
}

\section{ALLEN TORELL AND KIRK C. MCDANIEL}

\begin{abstract}
A general economic model to analyze optimal timing of brush control treatments and other range improvements was developed. The model was then applied to investments to control mesquite (Prosopis glandulosa Torr.) invading native rangeland in the Rolling Plains of Texas. Although a positive grass response from mesquite control would be anticipated for 5 years under average conditions, the economic optimum retreatment schedule is only 4 years. An increase in beef price shortens the optimal retreatment schedule, while an increase in treatment cost lengthens the optimal retreatment schedule. Implementing brush control treatments during a year favorable for high rate of top kill is an important economic consideration.
\end{abstract}

In an article that appeared in this journal, Ethridge et al. (1984) presented an economic analysis of chemical control of honey mesquite (Prosopis glandulosa Torr.) using 2,4,5-T (2,4,5-trichlorophenoxy acetic acid). They developed an analytical framework to analyze the profitability of brush control based upon the standard economic criterion of net present value (NPV). If the discounted present value of additional income generated from mesquite control over an assumed 5-year treatment life was greater than the cost of treatment, i.e. a positive NPV, the authors considered the brush control treatment to be economically feasible.

From the analysis presented by Ethridge et al. (1984) it is possible to consider an additional problem of determining when to retreat the mesquite canopy. When mesquite is sprayed, maximum grass yield generally occurs during the first 1 to 3 years after brush control, then production declines (Dahl et al. 1978). While a positive economic return can be obtained during later years of the treatment life, the deteriorating grass understory results in decreased beef production and annual returns. The implication is that it may be possible to make more money if the grass understory can be maintained in a more productive state through more frequent brush control treatments.

The retreatment or replacement problem can be described as follows. Nonforage brush species compete directly with desirable forage species for available light, water, and nutrients. As rangeland is invaded by brush, forage production gradually deteriorates and the carrying capacity of the range is decreased. Chemical spraying, chaining, bulldozing, burning or other methods of destroying the invading brush will rejuvenate grass production on the site. The replacement problem involves determining the optimal frequency of these brush control practices.

This paper investigates optimal timing of mesquite control when the rancher's goal is profit maximization. A sensitivity analysis is presented that indicates how changing the level of initial mesquite infestation, the level of treatment success (degree of top kill), discount rate, beef price, and treatment cost would affect the optimal timing of mesquite control practices.

\section{Methods and Procedures}

The equations of the Ethridge model, relating increased revenue from mesquite control, were used to define key physical, biological, and economic relationships for this study. Functions specified in the Ethridge model were used with no adjustments made; only the basic model formulation was altered. Beef prices, livestock production costs, and cost of mesquite control treatment were

Authors are assistant professor and associate professor, Department of Agricultural Economics and Agricultural Business and Department of Animal and Range Sciences, New Mexico State University, Las Cruces 88003.

This publication is New Mexico Experiment Station journal article no. 1164

Manuscript accepted 16 December 1985. taken directly from the Ethridge paper.

Unless otherwise stated, a 7\% discount rate was used to calculate the NPV of the stream of earnings from mesquite control treatment. This interest rate is taken as an expected real rate including a risk premium under the assumption of constant relative price levels. This differs from the $10 \%$ discount rate used by Ethridge et al. (1984).

\section{The Faustmann Model of Asset Replacement}

The basic model developed to make the replacement decision was formulated more than 135 years ago by Faustmann (1849). Many economic concepts of the Faustmann model, as briefly outlined here, were discussed in detail by Perrin (1972).

When deciding to treat a brush infested pasture again, the profit maximizing resource manager tries to choose the length between treatments that will maximize NPV calculated over all future cycles of improvement. This involves comparing the gains from keeping the current brush control treatment in place for 1 more year to the opportunity gains that could be realized by initiating the treatment at this time period.

The following relationships and definitions are used to define the economic model:

$$
\begin{aligned}
& \text { defender }= a \text { brush control treatment already in place, } \\
& \text { challenger }= \text { a brush control treatment that can replace (improve) a } \\
& \text { defender, } \\
& \mathbf{R}(t)= \text { the flow of added revenue from brush control when } \\
& \text { stand age since last treatment is } t \text { [equivalent to what } \\
& \begin{array}{l}
\text { Ethridge called Value of the Marginal Product } \\
\text { (VMP }) \text { ], }
\end{array} \\
& C(S, m)= \text { the present value of the stream of earnings from a chal- } \\
& \text { lenger brush control treatment to be replaced at age } S \\
& \text { by a series of } m \text { identical treatments, } \\
& \mathbf{K}=\begin{array}{l}
\text { cost of brush control incurred at the beginning of the } \\
\text { treatment period, }
\end{array} \\
& r=\text { the interest rate used in discounting future benefits. }
\end{aligned}
$$

The present value of the stream of returns associated with the initial treatment alone is given by

$$
C(S, 1)=\sum_{t=1}^{S}(1+r)^{-t} R(t)-K
$$

This equation represents the NPV criterion used in the Ethridge model to determine the economics of mesquite control, and is a common criterion used in many alternative range improvement economic analyses. Some finite life is assumed and the NPV of potential added returns resulting from the range improvement

Table 1. Descriptive statistics for variables in the $\mathrm{MP}_{\mathrm{G}}$ relationship as reported by Ethridge et al. (1984).

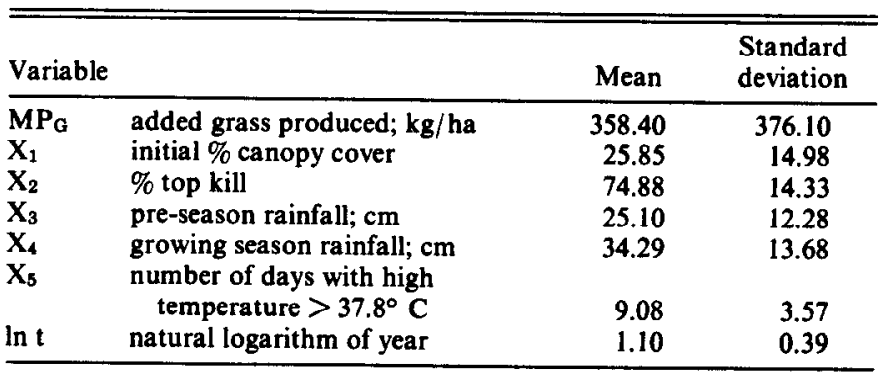


Table 2. NPV of mesquilte control calculated for average conditions.

\begin{tabular}{|c|c|c|c|c|c|c|}
\hline Year & $\begin{array}{c}\text { Additional grass } \\
\text { production } \\
\mathbf{M P a}\end{array}$ & $\begin{array}{l}\text { Additional beef } \\
\text { production } \\
\text { MPL }\end{array}$ & $\begin{array}{l}\text { Additional revenue } \\
\qquad \mathbf{R}(\mathbf{t})^{1}\end{array}$ & $\begin{array}{c}\text { Infinite series } \\
\text { factor } \\
\mathbf{A}(\mathbf{S})\end{array}$ & $\begin{array}{l}\text { NPV of initial } \\
\text { treatment } \\
\text { C(S,1) }\end{array}$ & 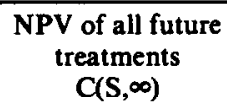 \\
\hline & $(\mathrm{kg} / \mathrm{ha})$ & (kg/ha) & (\$/ha) & & \multicolumn{2}{|c|}{$-(S / h a)$} \\
\hline 1 & 1048.6 & 15.2 & 16.27 & 15.2857 & -6.80 & -103.87 \\
\hline 2 & 615.0 & 8.9 & 9.54 & 7.9013 & 1.54 & 12.16 \\
\hline 3 & 361.3 & 5.2 & 5.61 & 5.4436 & 6.11 & 33.28 \\
\hline 4 & 181.3 & 2.6 & 2.81 & 4.2175 & 8.26 & 34.84 \\
\hline 5 & 41.7 & 0.6 & 0.65 & 3.4842 & 8.72 & 30.39 \\
\hline
\end{tabular}

Conditions: $26 \%$ initial canopy, $75 \%$ top kill, $25.1 \mathrm{~cm}$ pre-season rainfall, $34.3 \mathrm{~cm}$ growing season rainfall, 9 days $/$ year with high temperature $>37.8^{\circ} \mathrm{C}$. Assumes $9,526 \mathrm{~kg}$ of grass produces $137.9 \mathrm{~kg}$ of calf for market, net calf selling price of $\$ 1.07 / \mathrm{kg}$ (Calf market price of $\$ 1.62 / \mathrm{kg}$ and variable calf production cost of $\$ .55 / \mathrm{kg}$ ), a $7 \%$ discount rate and treatment costs of $\$ 22 /$ ha.

IAnnual revenue figures presented differ slightly from values given by Ethridge et al. (1984). Discussion with the authors indicate they converted from english units to metric units and rounding error explains the difference.

practice is calculated. The improvement is recommended if NPV is positive. However, the optimal decision rule should not be to maximize the NPV of earnings associated with only the first brush control treatment, $C(S, 1)$, but rather the NPV of earnings calculated over all future treatments, $\mathrm{C}(\mathrm{S}, \infty)$, which is given by

$$
\begin{aligned}
C(S, \infty) & =C(S, 1)+(1+r)^{-8} \mathrm{C}(S, 1)+(1+r)^{-28} \mathrm{C}(S, 1)+\ldots . \\
& =C(S, 1)\left[1+(1+r)^{-8}+(1+r)^{-28}+\ldots .\right]
\end{aligned}
$$

or

$$
\mathbf{C}(\mathbf{S}, \infty)=\mathbf{A}(\mathbf{S}) \cdot \mathbf{C}(\mathbf{S}, 1)
$$

where $A(S)=\left(1-(1+r)^{-8}\right)^{-1}=$ Infinite Series Factor, which is the present value of a perpetual annuity of $\$ 1$ received every $S$ years.

\section{Optimal Decision Rule}

The optimal replacement criterion, assuming profit maximization is the rancher's goal, requires the brush retreatment schedule be chosen to maximize $C(S, \infty)$ as given by equation (3). Perrin (1972) has shown this expression will be at a maximum when the following condition holds :

$$
\mathrm{R}(\mathrm{S}+1)=\mathrm{r} \bullet \mathbf{A}(\mathbf{S}) \bullet \mathbf{C}(\mathrm{S}, 1)
$$

This equation indicates the defender brush control treatment should be maintained until the incremental income from increasing $S$ equals marginal opportunity cost, which is the interest on the wealth realized from an S-year retreatment cycle. When retreatment age is optimal, returns in the forthcoming year, $R(S+1)$, will equal the flow of returns that would be realized by retreatment of the increasing brush canopy during this time period.

When the model is formulated in discrete form as it is here, the marginal condition given by equation 4 is not likely to be met exactly for a given integer number of years. Consequently, it is just as easy to evaluate the present value function, $C(S, \infty)$, as it is to evaluate the marginal conditions.

\section{Adaptation of the Ethridge Model}

In their model development, Ethridge et al. (1984) begin with an equation that defines the additional grass production associated with the mesquite control treatment. The equation was estimated in the following form ${ }^{2}$ :

$$
\begin{aligned}
M P_{G}=11.48+19.15 X_{1}+ & 23.72 X_{2}-15.56 X_{3}-13.50 X_{4}-41.97 X_{5} \\
& -625.6 \ln t
\end{aligned}
$$

where the variables of the equation along with mean levels of variables, as reported, are shown in Table 1.

To facilitate interpretation, all variables except time were held constant at mean levels and a simplified equation resulted. Using

\footnotetext{
Terrin included the salvage value of the asset in his model formulation. This salvage value can be excluded in this application since no asset is sold or salvaged at the time of brush retreatment.

${ }^{2}$ The coefficient presented by Ethridge et al. (1984) for the variable $X_{5}$ was -31.14. Discussion with the authors indicated this was in error and should have been the -41.97 outlined in equation (5)
}

data provided by Ethridge (Table 1), equation 5 indicates that with normal (average) temperature and rainfall conditions, controlling a $26 \%$ initial canopy cover and obtaining a $75 \%$ top kill will result in an increased grass production level of about $1,049 \mathrm{~kg} /$ ha the first year after treatment, 615 the second year, 361 the third year, 181 the fourth year, and 42 the fifth year. After this time, grass yield is estimated to be at or below pretreatment levels. The nearly instantaneous response of forage to mesquite control treatment is in contrast to the pinyon-juniper replacement problem analyzed by Cotner (1963) and Burt (1971), where grass recovery begins slowly, reaches a maximum after several years, and slowly declines.

In the Ethridge model, increased grass production is converted to increased beef production by multiplying $\mathrm{MPa}$ by a conversion factor, $\mathrm{k}$, which measures the efficiency rate at which grass is converted to beef ( $1 \mathrm{~kg}$ of grass was estimated to yield $.0145 \mathrm{~kg}$ of calf gain):

$$
M P_{L}=k\left(M P_{G}\right)
$$

$M P_{L}$ is the additional livestock production per unit of land associated with the mesquite control treatment.

Increased beef production is converted to increased revenue by multiplying $M P_{L}$ by a net selling price $\left(P_{L}\right)$ of $\$ 1.07 / \mathrm{kg}(\$ 1.62 / \mathrm{kg}$ gross selling price minus $\$ .55 / \mathrm{kg}$ production costs), which indicates an additional $\mathbf{~ k g}$ of marketable beef produces $\$ 1.07$ in revenue above added cost.

Combining these 3 relationships results in an annual revenue function (dollar value of additional grass) as given by:

$$
\mathbf{R}(t)=P_{L}\left(M_{P_{L}}\right)
$$

Given the initial assumptions about average rainfall and temperatures, initial canopy cover, percent top kill, beef prices and production costs, an estimate of increased annual revenue resulting from treatment with 2,4,5-T is obtained using equation 7 . It is estimated that brush control treatment would increase revenue by $\$ 16.27 /$ ha the first year after treatment, $\$ 9.54$ the second year, $\$ 5.61$ the third year, $\$ 2.81$ the fourth year, and $\$ 0.65$ the fifth year. After year 5 , the effect of the treatment on grass production, beef production, and annual revenue is negligible under the specification of the Ethridge model.

Once $R(t)$ is defined, the value of the present value functions $C(S, 1)$ and $C(S, \infty)$ can be calculated for alternative retreatment schedules by performing necessary calculations as given by equations (1) and (3) respectively. The only additional information needed is the treatment cost, estimated to be about $\$ 22 /$ ha in the Texas Rolling Plains (Ethridge et al. 1984).

\section{Model Assumptions and Limitations}

One might expect that the optimal rotation period for control of invading brush species would be lengthened following each successive treatment as the brush canopy is gradually diminished through continued control treatments. This suggests a dynamic model that 
accounts for percent brush canopy and level of top kill achieved with treatment (rate of treatment) should be used. For this model formulation, the revenue function would not only have time since last treatment as an argument but would also include brush canopy. Brush canopy would have to be tracked through time and the interaction of understory grass production and overstory brush canopy would have to be modeled explicitly. Treatment success or rate of treatment would determine mesquite canopy each time period and would be a decision variable of the model.

Data for this dynamic modeling approach are not presently available for mesquite (or any other brush species). Presently, biological data limit the refinement of model specification to consider only identical treatment cycles as we have done here.

An implicit assumption of the replacement model developed in this paper is that brush control results in the same level of brush kill, grass response, and increased level of economic return for each successive treatment. The level of brush kill from a given treatment is assumed to be unaffected by how recent the previous treatment was.

A second assumption of the model, as well as the Ethridge model, is that grazing intensity, grazing frequency, type of animal grazed and season of grazing does not affect brush encroachment rate or the expected forage response from brush contol treatment. Similar to the replacement problem on southwestern rangelands invaded by pinyon-juniper trees as studied by Cotner (1963) and Burt (1971), there is little literature that would support or refute the importance of grazing on the rate of encroachment or regrowth of mesquite. Grazing may be an important consideration for timing of mesquite control investment but, based on the lack of data indicating its relevance in this application, it has been ignored. However, grazing has been shown to be important in other cases. Torell (1984) has shown that grazing impact on the rate of sagebrush (Artemisia tridentata Nutt.) encroachment is an important consideration for timing of brush control investments for established crested wheatgrass (Agropyron cristatum (L.) Gaertr.) stands.

A third limitation is that the model is deterministic in nature and no probability or randomness of occurring events is assumed. This is a standard assumption made in many economic analyses.

\section{Results and Discussion}

\section{Optimal Retreatment Strategy Under Average Conditions}

The functional specification of the Ethridge model indicates a positive economic response would be realized for 5 years following mesquite control treatment. If only NPV of the first brush control treatment is considered [C(S,1) is maximized], the maximum treatment life of 5 years results in maximum net returns $(\$ 8.72 /$ ha) (Table 2). However, the infinite income stream, $(C(S, \infty)$, is maximized by retreating the mesquite canopy in only 4 years. $\mathrm{C}(\mathrm{S}, \infty)$ was estimated to be $\$ 34.84 /$ ha for a 4 -year treatment schedule, which is $\$ 4.45 /$ ha higher than with a 5-year retreatment schedule. Even a 3-year treatment schedule yields a higher level of NPV $(\$ 33.28 /$ ha) than letting the grass understory deteriorate to the fifth year $(\$ 30.39 / \mathrm{ha})$.

The implication, given the assumption of average conditions and prices, is that grass yield has deteriorated too far by the fifth year after treatment. Implementing brush control more frequently to maintain the grass understory in a more productive state would be more economical.

\section{Sensitivity Analysis}

\section{Alternative Levels of Mesquite Infestation}

As pointed out by Ethridge et al. (1984), as physical conditions of the range site change, the cost of herbicide application is increased, or if relative net beef price is altered, the economic feasibility of brush control may be altered. These differences may also imply a change in the optimal timing of investments to control mesquite. Consider a greater-than-average mesquite infestation with a $41 \%$ brush canopy (one standard deviation above the mean) as considered in the Ethridge paper. Under this condition, a positive influence of mesquite control is realized for 8 grazing seasons. The implication is that perhaps the retreatment period should be extended, but this result is not obtained. As indicated in Table 3,

Table 3. NPV of mesquite control calculated for alternative mesquite infestation levels.

\begin{tabular}{|c|c|c|c|c|c|c|}
\hline \multirow[b]{2}{*}{ Year } & & \multicolumn{5}{|c|}{ Initial Canopy Cover of Mesquite Infestation } \\
\hline & $\mathrm{MP}_{\mathrm{G}}$ & $\begin{array}{r}41 \% \\
\mathrm{C}(\mathrm{S}, 1)\end{array}$ & $\mathrm{C}(\mathrm{S}, \infty)$ & $\overline{\mathrm{MPG}}$ & $\begin{array}{l}-11 \% \\
\mathrm{C}(\mathrm{S}, 1)\end{array}$ & $C(S, \infty)$ \\
\hline & (kg/ha) & $(\$ /$ ha $)$ & (\$/ha) & $(\mathrm{kg} / \mathrm{ha})$ & $(\$ /$ ha) & (\$/ha) \\
\hline 1 & $1,336.9$ & -2.61 & -39.97 & 761.6 & -10.96 & -167.48 \\
\hline 2 & 903.3 & 9.63 & 76.05 & 328.0 & -6.51 & -51.46 \\
\hline 3 & 649.6 & 17.85 & 97.18 & 74.3 & -5.57 & -30.33 \\
\hline 4 & 469.6 & 23.41 & 98.74 & & & \\
\hline 5 & 330.0 & 27.06 & 94.29 & & & \\
\hline 6 & 216.0 & 29.30 & 87.80 & & & \\
\hline 7 & 119.5 & 30.45 & 80.72 & & & \\
\hline 8 & 36.0 & 30.78 & 73.63 & & & \\
\hline
\end{tabular}

Conditions: Various initial mesquite canopy covers before treatment with all other conditions the same as given in Table 2.

although NPV of the first treatment $[C(S, 1)]$ is increased for each of the 8 years of treatment life, a 4-year rotation still maximizes the NPV of the infinite income stream $[\mathrm{C}(\mathrm{S}, \infty)]$ with an estimated value of $\$ 98.74 / \mathrm{ha}$.

The general increase in the values of $C(S, 1)$ and $C(S, \infty)$, over levels obtained under average conditions, results from greater additional grass production from mesquite control when the level of mesquite infestation is higher (see Ethridge et al. 1984, Figure 2). Increased grass response increase the level of beef production and annual revenues over the treatment life.

If the initial level of mesquite canopy were only $11 \%$ ( 1 standard deviation below the mean), chemical control treatments should not be implemented. NPV of benefits is not enough to pay for the $\$ 22 /$ ha treatment cost. Although not discussed, this same conclusion would be reached using the Ethridge model.

\section{Alternative Levels of Top Kill}

Ethridge et al. (1984) noted that spraying under more advantageous environmental conditions affects the success of brush control. If, for example, a "good" year at the time of spraying resulted in top kill being increased from an average of $75 \%$ to $89 \%$ (1 standard deviation above the mean), annual returns would be greatly increased.

NPV of the initial treatment, if a 5-year life is assumed, was increased from $\$ 8.72 /$ ha with an average $75 \%$ top kill (Table 2 ) to $\$ 30.39 /$ ha if an $89 \%$ top kill could be achieved (Table 4). A rancher could make nearly the same discounted return with 1 treatment at an $89 \%$ top kill as he could from all future spray treatments, if

Table 4. NPV of mesquite control calculated for alternative top kill levels.

\begin{tabular}{|c|c|c|c|c|c|c|}
\hline \multirow[b]{2}{*}{ Year } & \multirow[b]{2}{*}{$\mathbf{M P} \mathbf{P}_{\mathbf{G}}$} & \multirow[b]{2}{*}{$\begin{array}{l}-89 \%- \\
C(S, 1)\end{array}$} & \multicolumn{3}{|c|}{ Level of Top Kill } & \multirow[b]{2}{*}{$\mathrm{C}(\mathrm{S}, \infty)$} \\
\hline & & & $\overline{C(S, \infty)}$ & $\overline{\mathrm{MPG}}$ & $\begin{array}{l}-61 \% \\
\mathrm{C}(\mathrm{S}, 1)\end{array}$ & \\
\hline & (kg/ha) & $(\$ / h a)$ & (\$/ha) & $(\mathrm{kg} / \mathrm{ha})$ & (\$/ha) & (\$/ha) \\
\hline 1 & $1,389.2$ & -1.86 & -28.38 & 709.4 & -11.71 & -179.05 \\
\hline 2 & 955.6 & 11.09 & 87.65 & 275.8 & -7.98 & -63.03 \\
\hline 3 & 701.9 & 19.98 & 108.78 & 22.1 & -7.70 & -41.90 \\
\hline 4 & 521.9 & 26.10 & 110.33 & & & \\
\hline 5 & 382.3 & 30.39 & 105.88 & & & \\
\hline 6 & 268.3 & 33.16 & 99.39 & & & \\
\hline 7 & 171.8 & 34.82 & 92.31 & & & \\
\hline 8 & 88.3 & 35.62 & 85.22 & & & \\
\hline 9 & 14.6 & 35.74 & 78.37 & & & \\
\hline
\end{tabular}

Conditions: Various top kill rates with all other conditions as given in Table 2. 
the top kill was only $75 \%$. Therefore, choosing a year for initial and subsequent treatments in which a high level of top kill could be expected is an important consideration.

Increasing top kill to $89 \%$ does not alter the optimal 4-year rotational period. NPV of the maximum infinite income series was increased from $\$ 34.84$ (Table 2) to $\$ 110.33$ (Table 4), but the maximum was still obtained during the fourth year. If only a $61 \%$ top kill was expected from mesquite control (1 standard deviation below the mean), brush control should not be implemented. Because of a reduced level of grass response, the NPV of additional annual revenue would be less than treatment costs for all years in which a positive forage benefit was realized.

\section{Alternative Discount Rates}

When the discount rate is increased, the NPV of a future income stream is diminished. Future benefits are not worth as much in present value terms at a higher discount rate. One might surmise, therefore, that an increased discount rate would always shorten the optimal rotation period. This is not necessarily the case. An increase in discount rate has 2 conflicting effects: it decreases the present value of the annuity $\mathrm{C}(\mathrm{S}, 1)$ but it also increases the factor $r \cdot A(S)$ of the marginal condition given by equation 4 . If the negative effect of an increase in $r$ outweights the positive effect, then the optimal rotation period will in fact be shortened. ${ }^{3}$ As outlined in greater detail by Torell (1984) and Perrin (1972) the net effect of an increased discount rate depends upon the level of $r$ and the path of $R(t)$ up to age $S$.

Table 5. NPV of mesquite control calculated for alternative discount rates.

\begin{tabular}{|c|c|c|c|c|c|c|}
\hline \multirow[b]{3}{*}{ Year } & & & \multicolumn{3}{|c|}{ Discount Rate } & \\
\hline & \multicolumn{2}{|c|}{$-\quad 2 \%$} & \multicolumn{2}{|c|}{$-3 \%$} & \multicolumn{2}{|c|}{ - $-10 \%$} \\
\hline & $\mathrm{C}(\mathrm{S}, 1)$ & $\mathrm{C}(\mathrm{S}, \infty)$ & $\mathrm{C}(\mathrm{S}, 1)$ & $C(S, \infty)$ & $\mathrm{C}(\mathrm{S}, \mathbf{1})$ & $\mathrm{C}(\mathrm{S}, \infty)$ \\
\hline & & & $\ldots$ & ha) - - - & & \\
\hline 1 & -6.05 & -308.55 & -6.20 & -213.03 & -7.21 & -79.31 \\
\hline 2 & 3.12 & 80.37 & 2.79 & 48.58 & 0.68 & 3.89 \\
\hline 3 & 8.40 & 145.69 & 7.92 & 93.32 & 4.89 & 19.65 \\
\hline 4 & 11.00 & 144.47 & 10.42 & 93.43 & 6.81 & 21.48 \\
\hline 5 & 11.59 & 122.93 & 10.98 & 79.90 & 7.21 & 19.02 \\
\hline
\end{tabular}

Conditions: Various discount rates with all other conditions the same as given in Table 2 .

As indicated in Table 5, for the functional specification given by the Ethridge model, an increase in discount rate lengthens the optimal rotation period. At the $7 \%$ discount rate originally assumed in the analysis, the optimal rotation period was every 4 years (Table 2). At a discount rate of $2 \%$, the optimal rotation period is shortened to every 3 years, with $C(S, \infty)$ reaching a maximum value of $\$ 145.69$ at this point (Table 5 ). At a $3 \%$ rate, the maximum value of $\mathrm{C}(\mathrm{S}, \infty)$ is nearly equivalent during year 3 (\$93.32/ha) and during year $4(\$ 93.43 / \mathrm{ha})$. For all practical purposes, one is indifferent between treatment during either of these years. A $10 \%$ discount rate yields an optimal rotation period of 4 years.

\section{Alternative Beef Prices}

An increase in beef price affects revenue in all future years of the treatment cycle. Depending upon the time path of annual revenue, the optimal retreatment schedule can be increased or decreased as net beef price is increased (Torell 1984). With the specification of the revenue function in the Ethridge model, an increase in beef price shortens the optimal rotation period. If the market beef price is increased to $\$ 1.98 / \mathrm{kg}$ ( $\$ 1.43 / \mathrm{kg}$ net selling price), the optimal rotation period is shortened to 3 years (Table 6 ). If beef price is reduced to $\$ 1.43 / \mathrm{kg}$ ( $\$ 0.88 / \mathrm{kg}$ net selling price), similar to the result obtained at the original assumed market price level of $\$ 1.62 / \mathrm{kg}$, a 4-year rotation is optimal.

\section{Alternative Treatment Costs}

Unlike an increase in beef price or discount rate, where the

In the discrete time case as formulated here, the optimal rotation period may remain unchanged over a range of discount rates.
Table 6. NPV of mesquite control calculated for alternative beef prices.

\begin{tabular}{|c|c|c|c|c|}
\hline \multirow[b]{3}{*}{ Year } & \multicolumn{4}{|c|}{ Market Beef Prices } \\
\hline & \multicolumn{2}{|c|}{$-\ldots 1.98 / \mathrm{kg}$} & \multicolumn{2}{|c|}{$-\$ 1.43 / \mathrm{kg}$} \\
\hline & $\mathrm{C}(\mathrm{S}, 1)$ & $C(\$, \infty)$ & $\mathrm{C}(\mathrm{S}, 1)$ & $C(S, \infty)$ \\
\hline & & $-1-1$ & & \\
\hline 1 & -1.68 & -25.68 & -9.50 & -145.14 \\
\hline 2 & 9.46 & 74.73 & -2.64 & -20.87 \\
\hline 3 & 15.57 & 84.77 & 1.12 & 6.11 \\
\hline 4 & 18.44 & 77.78 & 2.89 & 12.18 \\
\hline 5 & 19.06 & 66.40 & 3.27 & 11.38 \\
\hline
\end{tabular}

Conditions: Various market beef prices with all other conditions the same as given in Table 2.

direction of change of optimal rotation age can either increase or decrease depending upon specific functional specification, an increase in treatment cost will necessarily increase (or leave unaltered in the discrete time case) the optimal retreatment schedule (Torell 1984). As treatment cost increases, more money could be made by incurring the cost on a less frequent basis.

Consider, as an example, if the cost of treatment were $\$ 30 /$ ha instead of the assumed $\$ 22 /$ ha. With the higher treatment cost, NPV would not be positive except with a 4- or 5-year treatment schedule. The NPV of the revenue stream derived from the first treatment, $C(S, 1)$, after a 5-year life would only be $\$ 0.72 /$ ha (Table 7). NPV of the infinite income stream, $\mathrm{C}(\mathrm{S}, \infty)$, would reach a maximum during the fifth year at $\$ 2.52 /$ ha.

Table 7. NPV of mesquite control for alternative treatment costs.

\begin{tabular}{|c|c|c|c|c|}
\hline \multirow[b]{3}{*}{ Year } & \multicolumn{4}{|c|}{ Treatment Cost } \\
\hline & \multicolumn{2}{|c|}{ ___ $\$ 30 / \mathrm{ha}$} & \multicolumn{2}{|c|}{ - $\$ 15 /$ ha --} \\
\hline & $\mathrm{C}(\mathrm{S}, 1)$ & $\mathrm{C}(\mathrm{S}, \infty)$ & $C(S, 1)$ & $\mathrm{C}(\mathrm{S}, \infty)$ \\
\hline & & $-1-1$ & & \\
\hline 1 & -14.80 & -226.16 & 0.20 & 3.13 \\
\hline 2 & -6.46 & -51.06 & 8.54 & 67.46 \\
\hline 3 & -1.89 & -10.27 & 13.11 & 71.39 \\
\hline 4 & 0.26 & 1.10 & 15.26 & 64.36 \\
\hline 5 & 0.72 & 2.52 & 15.72 & 54.78 \\
\hline
\end{tabular}

Conditions: Various treatment costs with all other conditions the same as given in Table 2.

If $2,4,5-\mathrm{T}$, or some other herbicide yielding identical grass response, could be applied for a reduced cost of only $\$ 15 /$ ha then the optimal rotation period would be shortened to only 3 years. $\mathrm{C}(\mathrm{S}, \infty)$ would reach a maximum of $\$ 71.39 /$ ha at this point (Table 7).

\section{Conclusions}

Results of this study indicate mesquite control should not be postponed until the forage stand has fully deteriorated. If the forage base diminishes each year after mesquite control, then a rancher can make more money by respraying the brush to maintain the grass understory in a more productive state. Optimal timing for retreatment of mesquite was estimated to be 1 or 2 years before the stand returns to pretreatment production levels. Only if treatment cost or discount rate is exceptionally high would respraying the final year of treatment life be optimal.

The present value of all future brush control treatments is increased greatly when a high level of treatment success is achieved. Therefore, the ultimate time to retreat the brush canopy may not be the exact year as estimated here. Rather, as evidenced by the tripling of estimated NPV when a high level of top kill is attained (as compared to only average levels of top kill), waiting for ideal spray conditions is an important consideration. Forage response, rainfall and temperature patterns for the area are important in determining optimal conditions for spraying mesquite. These conditions have been described by Scifres (1973, 1980), Fisher et al. 
(1956), Dahl and Sosebee (1984) and Leifeste (1983), among others.

Further research is needed to refine the economic model to include level of top kill and a dynamic brush canopy. A more dynamic model for mesquite control, which includes various physical and biological interactions is not definable with the current level of response data that is available. Only with additional longterm research can model refinements and improvements be made.

\section{Literature Cited}

Burt, O.R. 1971. A dynamic economic model of pasture and range improvements. Amer. J. Agr. Econ. 53:197-205.

Cotner, M.S. 1963. Optimum timing of long-term resource improvements. J. Farm Econ. 45:732-748.

Dahl, B.E., and R.E. Sosebee. 1984. Timing - the key to herbicidal control of mesquite. Texas Tech Univ. College of Agr. Sci. Management No. 2.

Dahl, B.E., R.S. Sosebee, J.P. Goen, and C.S. Brumley. 1978. Will mesquite control with 2,4,5-T enhance grass production? J. Range Manage. 31:129-131.

Ethridge, B.E., B.E. Dahl, and R.E. Sosebee. 1984. Economic evaluation of chemical mesquite control using 2,4,5-T. J. Range Manage. 37:152-156.

Faustmann, M. 1849. On the determination of the value which forest land and immature stands possess for forestry. English edition edited by $\mathbf{M}$. Gare, Oxford Institute, Paper 42, 1968, entitled "Martin Faustmann and the Evolution of Discounted Cash Flow.

Fisher, C.E., C.H. Meadows, and R. Behrens. 1956. Some factors that influence the effectiveness of 2,4,5-T trichlophenoxy acetic acid in killing mesquite. Weed Sci. 4:139-147.

\section{Range Science Department Colorado State University Fort Collins, Colorado}

\section{POSITION: Research Associate}

QUALIFICATIONS: M.S. degree in Range Science or closely associated discipline with experience in economics, preferably risk analysis.

DUTIES AND RESPONSIBILITIES: This person would be expected to develop appropriate models to describe ranch firms and evaluate risk. He would live in residence at the Southeastern Colorado Research Center at Springfield and be responsible for range research initiation, data analysis, and reporting. The person would work with ranchers in research demonstration programs.

STARTING DATE: September 1, 1986

SALARY: Commensurate with experience and qualifications. Salary range is $\$ 17,000$ to $\$ 21,000$ per year. CSU benefits are applicable.

APPLICATIONS: Please send letter of application, detailed resume, and names of three persons for recommendation to: E.T. Bartlett, Range Science Department, Colorado State University, Fort Collins, Colorado 80523, telephone (303) 491-7256.

\section{APPLICATION DEADLINE: August 15, 1986}

Colorado State University is an EEO/AA employer E.O. Office: 314 Student Service Building.
Lelfeste, W.F. (ed.). 1983. Mesquite control in New Mexico. New Mexico State Univ. Coop. Ext. Serv. Circ. 505.

Perrin, R.K. 1972. Asset replacement principles. Amer. J. Agr. Econ. 54:60-67.

Scifres, C.J. (ed.). 1973. Mesquite: distribution, ecology, uses, control, economics. Texas Agr. Exp. Sta. Res. Management 1.

Seifres, C.J. 1980. Brush management principles and practice for Texas and the southwest. Texas A\&M Univ. Press College Station.

Torell, L.A. 1984. Economic optimum stocking rates and retreatment schedule for crested wheatgrass stands. Ph.D. Thesis, Utah State University.

\section{Faculty Position Department of Range Science Utah State University}

POSITION: Twelve-month tenure-tract appointment at the Assistant Professor or Associate Professor level. This is a teaching and research position that requires specalization in range improvements. Starting date October 30, or as soon as possible thereafter.

QUALIFICATIONS: PhD in range science or closely related field. First-hand, practical experience in range improvements, especially brush management using fire or herbicide treatments. Experience in revegetation desriable. Sensitivity to public perceptions of range resource management. Ability and willingness to do research in interdisciplinary teams. A commitment to teaching excellence.

DUTIES: Teach a senior undergraduate course in range improvements plus a more advanced course in the successful applicant's specific area of interest. Be prepared to teach one other basic course in the range science curriculum and lend support to student activities. Conduct research on improving productivity of Intermountain rangelands that involves such range improvement tools as vegetation manipulation, water developments, fencing and grazing management. Develop and evaluate range improvement practices in the context of multipleuse management and economic considerations. Serve as a resource and associate for extension specialists in the Department. Work in collaboration with other USU faculty and with researchers in government organizations.

SALARY: Commensurate with qualifications and experience.

APPLICATION: Prospective candidates should send a resume, transcripts of undergraduate and graduate education, a statement of research interests and relevant reprints, and the names, addresses and telephone numbers of three references to: Dr. B.E. Norton, Department of Range Science, Utah State University UMC 5230, Logan, UT 84322. Applications accepted until August 30, 1986, or until a suitable applicant is found.

UTAH STATE UNIVERSITY IS AN EQUAL OPPORTUNITY/AFFIRMATIVE ACTION EMPLOYER 